\title{
Minerals and vitamins and the risk of bladder cancer: results from the New Hampshire Study
}

\author{
Maree T. Brinkman • Margaret R. Karagas • \\ Michael Scott Zens • Alan Schned • Raoul C. Reulen • \\ Maurice P. Zeegers
}

Received: 1 May 2009/Accepted: 10 December 2009/Published online: 31 December 2009

(c) The Author(s) 2009. This article is published with open access at Springerlink.com

\begin{abstract}
Objective Although the effect of fruit and vegetables on the risk of bladder cancer has been widely studied, little is known about their micronutrient components. Our aim was to investigate associations between minerals and vitamins and bladder cancer.

Methods A case-control study was conducted in New Hampshire, USA. Dietary data were collected from 322
\end{abstract}

\footnotetext{
M. T. Brinkman ( $ه)$

Cancer Epidemiology Centre, The Cancer Council Victoria,

1 Rathdowne Street, Carlton, VIC 3053, Australia

e-mail: Maree.Brinkman@cancervic.org.au;

maree.brinkman@optusnet.com.au
}

M. T. Brinkman · M. P. Zeegers

Department of General Practice, Katholieke Universiteit, Leuven, Belgium

M. R. Karagas · M. S. Zens

Section of Biostatistics and Epidemiology, Department of Community and Family Medicine, Dartmouth Medical School and Norris-Cotton Cancer Centre, Lebanon, NH, USA
A. Schned
Department of Pathology, Dartmouth Medical School,
Lebanon, NH, USA

\section{R. C. Reulen}
Centre for Childhood Cancer Survivor Studies,
University of Birmingham, Birmingham, UK

\section{P. Zeegers}

Unit of Genetic Epidemiology, Department of Public Health and Epidemiology, University of Birmingham, Birmingham, UK

\section{P. Zeegers}

Department of Complex Genetics, Nutrition and Toxicology

Research Institute, University of Maastricht, Maastricht,

The Netherlands cases and 239 controls using a 121-item food frequency questionnaire. Odds ratios (ORs) and 95\% confidence intervals (CIs) were calculated using logistic regression adjusting for sex, age, smoking characteristics, and energy intake.

Results The ORs $(95 \%$ CI) for highest quartile versus lowest quartile for total intake of vitamin $\mathrm{E}$ was $0.66(0.36$ $1.20 ; p$ trend $=0.09)$ and $0.49(0.21-1.17 ; p$ trend $=0.13)$ for dietary phosphorus. The odds of bladder cancer for heavy smokers with the highest total intake of vitamin $\mathrm{E}$, carotenoids, and niacin were $0.58(0.34-0.99), 0.62(0.36-$ $1.09)$, and $0.66(0.39-1.14)$, respectively. Higher total intakes of carotenoids, vitamin $\mathrm{D}$, thiamin, niacin, and vitamin $\mathrm{E}$ were inversely related to bladder cancer risk among older individuals.

Conclusion Our findings suggest further investigation of the effect of vitamin E, carotenoids, vitamin D, thiamin, and niacin on bladder cancer risk may be warranted. Future studies should focus on high risk groups such as heavy smokers and older individuals.

Keywords Bladder cancer - Minerals · Vitamins . Carotenoids · Folate

\section{Introduction}

In 2002, a global study reported that the US had among the highest reported age standardized incidence rate of bladder cancer $(24.1 / 100,000)$ [1]. The National Cancer Institute (NCI) estimated that in 2009, there would be approximately 70,980 new cases and 14,330 deaths from bladder cancer in the USA [2].

Despite reduced exposure to established risk factors such as smoking, aromatic arylamines (occupation), and 
schistosomal infection, the incidence of bladder cancer in the USA remains high [3]. This is consistent with other studies suggesting that these risk factors only partly explain bladder cancer etiology [4, 5]. One etiologic study [6] investigating regional variation in bladder cancer rates across the USA also considered diet as a possible risk factor.

Several studies [7-14] have reported that dietary factors such as fruit and vegetables may be protective against bladder cancer. However, there is a lack of consistent evidence between the intake of related micronutrient components of fruits and vegetables and reduced risk of the disease [5]. The Second Expert Report on nutrition and cancer by the World Cancer Research Fund/American Institute of Cancer Research states that the evidence was too limited to conclude that any food or nutrient directly influences the risk of bladder cancer [15]. Conversely, a recent systematic review [16] as part of a WHO consultancy report found that nutrient components of specific fruits and vegetables have a possible inverse association with bladder cancer. It is these dietary micronutrients or their metabolites that actually come into direct contact with the bladder epithelium and thus in theory could be protective [10].

Vitamin A is obtained from the diet as preformed vitamin A from animal products and as carotenoids including both provitamin A and non-provitamin A carotenoids from plant foods [15]. An inverse association between vitamin A intake and bladder cancer has been reported in some studies [17, 18], but not others [3, 19-21]. Inconsistencies may be due to many earlier studies not distinguishing between these dietary sources [10]. Some recent studies suggest that it is the carotenoids [8, 22-24] ( $\alpha$-carotene [8], $\beta$-carotene [8, 25], $\beta$-cryptoxanthin [21], lycopene [8], lutein/zeaxanthin [8], and not retinol $[10,23,26]$ that influences the risk of bladder cancer. Although, other studies have reported the opposite effects, with some finding that retinol may actually be protective [18, 27-29] and others that the carotenoids have no effect $[3,10,19,30,31]$.

The relationship between bladder cancer and vitamin $\mathrm{C}$ and $\mathrm{E}$ also appears to be unclear with some studies reporting potential inverse associations (vitamin $\mathrm{C}$ : [29, 32, 33]; vitamin E: [20, 27]) and others no associations at all (vitamin C: [3, 19, 21, 23, 25]; vitamin E: [3, 19, 21, 23, 25, 31]).

Deficiencies in folic acid, vitamins B3 (niacin), B6, B12, have been reported to mimic radiation damage to DNA and possibly lead to the initiation of cancer [34]. However, there is only limited literature available on the association between water-soluble B-group vitamins and risk of bladder cancer, and the findings have been inconsistent [20, 21, 23, 25, 28, 35].

Cohen [36] reviewed the effect of diet on bladder cancer risk. He concluded that the potential for certain dietary minerals to influence urine composition and hence bladder carcinogenesis observed in animal studies needed further evaluation before extrapolation could be made to human populations. To date, few epidemiological studies have investigated the effect of dietary minerals such as sodium [20, 23], potassium [20], calcium [20, 23, 26], magnesium [20], and iron [20, 26] on the risk of developing bladder cancer.

Micronutrient deficiencies could provide a possible explanation for why an estimated $25 \%$ of the US population who consume the least fruit and vegetables have double the cancer rate [34]. The aim of our study was to investigate the association between major dietary minerals and vitamins and the risk of bladder cancer in a US population from a region with a high incidence rate [37].

\section{Methods}

\section{Study population}

A population-based case-control study was conducted in New Hampshire, USA. Details of the study have been reported previously [38, 39]. Briefly, bladder cancer cases were identified from the New Hampshire State Department of Health and Human Services Cancer Registry as histologically confirmed, primary bladder cancer diagnosed between 1 July 1998 and 31 December 2001. To be eligible for inclusion in the study, all cases had to be New Hampshire residents aged between 25 and 74, have a listed phone number and speak English. Physician consent was obtained before contacting potential participants. Of the 472 potentially eligible cases we contacted, a total of 398 (84\%) were interviewed for the study. For efficiency, controls were shared with another study on non-melanoma cancer covering a reference period from 1 July 1997 to 30 March 2000 [40]. Controls less than 65 years of age were selected from lists obtained from the New Hampshire Department of Transportation. Controls 65 years of age and older were chosen from data files provided by the Centers for Medicare \& Medicaid Services (CMS) of New Hampshire. Controls were randomly assigned a comparable reference date to case group dates of diagnoses [41]. A total of 526 controls $(76 \%)$ were interviewed from a potential 694 confirmed eligible participants.

\section{Data collection}

Extensive in-person interviews were conducted with consenting participants, usually in the homes of the participants. Data were collected on participants' socio-demographic information such as education level, residence, occupation (history), medical history, lifestyle factors (including tobacco smoking), household water supply, and family history of 
cancer. Interviewers were blind to case/control status and interviews were tape recorded with subjects' consent (less than $5 \%$ refused to have the interview taped) to ensure consistent quality of the interview and clarification of details. Cases were also asked if they held a driver's license or a Medicare enrollment card for comparability with controls [42].

\section{Dietary data}

Interviews which included dietary assessment took place between 2000 and 2003 for both cases and controls (for $95 \%$ of subjects). As data were unavailable for 150 cases and 455 controls; a total of 322 cases and 239 controls were included in the dietary analyses of this study. Subjects from whom dietary data were collected were comparable to those who did not provide dietary data with respect to age, sex, and smoking history (data not shown).

Dietary information was collected from a 121-item semiquantitative food frequency questionnaire (FFQ) that was developed by Willett et al. for the Nurses' Health Study [43]. Participants were asked about their usual dietary intake for the previous 12-month period. Foods items were assigned to seven broad categories. These included dairy, fruit, vegetables, eggs and meat, breads, beverages, and baked goods. There was a list of nine common mineral and vitamin supplements to choose from which included the following: multiple vitamins (participants were asked to report the individual vitamins within this category), vitamins A, C, B6 and $\mathrm{E}$, selenium, iron, zinc, and calcium. Additional questions covered folic acid, vitamin D, vitamin B complex, cod liver oil, omega 3 fatty acids, iodine, copper, Brewer's yeast, $\beta$-carotene, magnesium, and an open ended option, "other." Participants were provided with options for duration of supplement intake ranging from " 0 " to $10+$ years.

Frequency options ranged from never to six or more times a day. Nutrient intake was calculated by multiplying frequency of each food item on the FFQ by the nutrient content for the specific portion size [44]. Food composition data were based primarily on data from the United States Department of Agriculture (USDA) [45].

We investigated vitamins that had a biologically plausible association with bladder cancer and "macro-minerals", which are required in quantities greater than $100 \mathrm{mg}$ per day e.g., sodium, potassium, calcium, phosphorus, and magnesium [20]. An exception was iron, which was included due to its physiological function and potential to influence the risk of bladder cancer [34].

\section{Statistical analysis}

We investigated the association between total mineral and vitamin intake, which included micronutrients from both dietary and supplemental sources and bladder cancer risk. The intake of carotenoids, folate, and vitamin B12 were measured in micrograms $(\mu \mathrm{g})$ per day. All other vitamins including, B1 (thiamin), B2 (riboflavin), B3 (niacin), vitamin $\mathrm{C}$ and vitamin $\mathrm{E}$, and minerals (sodium, potassium, calcium, phosphorus, magnesium, and iron) were calculated in milligrams (mg) per day except for vitamin D intake, which was calculated in international units (IU). The data were analyzed in quartiles based on the control group distributions. ORs and corresponding 95\% CIs were calculated using logistic regression analysis. Adjustment was made for a number of possible confounding variables including sex, age, cigarette smoking status (current/noncurrent smoker), pack years of cigarette smoking (categories: $0<10,10<20,20<30,30<40,40<50$, $\geq 50$; calculated by dividing the number of cigarettes smoked per day by 20 and multiplying by the number of years smoked) and total energy intake (quartiles for kcal/day). Additional adjustment for other potential confounders, total fat intake (fat-soluble vitamins), alcohol and coffee consumption (water-soluble vitamins) did not alter the associations between micronutrients and bladder cancer. Minerals and vitamins were dichotomized according to median intakes by controls. Odds ratios and $95 \%$ CIs were calculated to investigate potential differences between invasive and noninvasive bladder cancer. We also performed additional analyses to assess the effects of minerals and vitamins from both dietary and supplemental sources separately. Intake of nutrients from dietary sources were analyzed in quartiles using the same statistical model for total intake of minerals and vitamins. We estimated the intake of minerals and vitamins from supplements by subtracting dietary intake from total nutrient intake. Due to the relatively small contribution to mineral and vitamin intake by supplements in this study population, these nutrients were dichotomized according to average intake of controls. Likelihood ratio tests were conducted to test for trend by assigning an integer to each quartile of the nutrient e.g., 1-4 then fit the term as a continuous variable in the model. The joint effects of specific nutrients and smoking status/history and age were also investigated. Nutrients and age were dichotomized into high and low categories based on median values of the controls. Smoking status was dichotomized into never/ever smoker, cigarettes per day into high and low categories $(<20 / \geq 20$ cigarettes per day) and duration of smoking ( $<27$ years/ $\geq 27$ years). We used the likelihood ratio test to evaluate interaction, i.e., comparing the log likelihood of regression models with and without the interaction term included. The false-positive report probability (FPRP) was employed to assess the probability of no true association between nutrients and the risk of bladder cancer given a statistically significant finding [46]. This test takes into account three factors that determine the 
probability that a statistically significant result may actually be a false-positive finding. These are (1) prior probability of an association; (2) the alpha-level, and (3) statistical power to detect an odds ratio for the alternative hypothesis at a given alpha-level or $p$ value. We used previously reported arbitrary values for these factors: 0.05 (alpha-level), 0.25 (prior probability), and 0.5 (false-positive report probability) $[46,47]$.

All reported $p$ values were two-sided and values less than or equal to 0.05 were considered to be statistically significant. The statistical software package Stata/SE 10.0 (Stata Corporation, College Station, TX, USA) was used for all statistical analyses.

\section{Results}

Study characteristics

Table 1 presents the frequency distributions of selected study characteristics for the 322 cases and 239 controls for

Table 1 Distribution of bladder cancer cases and controls by demographic characteristics and bladder cancer risk factors

\begin{tabular}{|c|c|c|}
\hline & $\begin{array}{l}\text { Cases } \\
\text { number }(\%)\end{array}$ & $\begin{array}{l}\text { Controls } \\
\text { number }(\%)\end{array}$ \\
\hline Total & 322 & 239 \\
\hline \multicolumn{3}{|l|}{$\operatorname{Sex}^{*}$} \\
\hline Men & $237(74)$ & $138(58)$ \\
\hline Women & $85(26)$ & $101(42)$ \\
\hline Age (years) [mean (SD)] & $62(9.2)$ & $60.7(10.6)$ \\
\hline \multicolumn{3}{|l|}{ Smoking status* } \\
\hline Never smokers & $56(17.4)$ & $95(39.7)$ \\
\hline Ex-smokers & $162(50.3)$ & $103(43.1)$ \\
\hline Current smokers & $104(32.3)$ & $41(17.2)$ \\
\hline Years smoking [mean (SD)]* & $32.2(14)$ & $27.4(15)$ \\
\hline Cigarettes/day [mean (SD)]* & $26.7(14.8)$ & $22.3(15.6)$ \\
\hline $\begin{array}{l}\text { Total calories kcal/day } \\
{[\text { mean }(\mathrm{SD})]}\end{array}$ & $1962.56(790.72)$ & $1887.74(706.64)$ \\
\hline Total fat g/day [mean (SD)] & $71.74(32.96)$ & $69.77(31.76)$ \\
\hline $\begin{array}{l}\text { Total alcohol g/day } \\
\text { [mean (SD)] }\end{array}$ & $7.91(15.84)$ & $8.29(14.45)$ \\
\hline $\begin{array}{l}\text { Total coffee g/day } \\
{[\text { mean (SD)] }}\end{array}$ & $227.41(210.13)$ & $216.57(192.88)$ \\
\hline \multicolumn{3}{|l|}{ Tumor stage at diagnosis } \\
\hline Carcinoma in situ (\%) & $16(5)$ & \\
\hline Non-invasive/low grade $(\%)$ & $190(59)$ & \\
\hline Non-invasive/high grade (\%) & $23(7)$ & \\
\hline Invasive (\%) & 93 (29) & \\
\hline
\end{tabular}

$S D$ standard deviation

* Statistically significant differences between cases and controls; $p<0.05$ whom dietary data were available for analyses in this study. Bladder cancer cases consisted of approximately three times more men $(74 \%)$ than women. A majority of both cases and controls were in the older age group (60 years and over). There was a higher prevalence of current smokers and greater number of both cigarettes smoked per day and years smoked among cases compared with the controls. We detected no statistically significant differences between cases and controls for calorie, total fat, alcohol, or coffee intake.

Total intake of minerals and vitamins and the risk of bladder cancer

Table 2 shows the ORs and 95\% CIs for bladder cancer and total intake (including dietary and supplemental sources) of fat-soluble and water-soluble vitamins. We observed a borderline statistically significant inverse association between total intake of vitamin $\mathrm{E}$ and bladder cancer (highest vs. lowest quartile, OR: 0.66; 95\% CI: $0.36-1.20 ; p$ trend $=0.09$ ). No statistically significant ORs were observed when comparing the highest quartile of intake with the lowest quartile for carotenoids as a group or for any of the individual carotenoids, $\alpha$-carotene, $\beta$-carotene, $\beta$-cryptoxanthin, lycopene, or lutein/zeaxanthin. Although the point estimate for vitamin D was well below one, this also did not reach statistical significance (OR: 0.58; 95\% CI: 0.31-1.06; $p$ trend $=0.22$ ).

Among the water-soluble vitamins, the OR for niacin and bladder cancer was of borderline statistical significance (highest vs. lowest quartile OR: 0.56; 95\% CI: 0.31-1.02). No other associations were observed between bladder cancer and any other B-group or water-soluble vitamins, which included thiamin, riboflavin, B6, B12, and folate or vitamin C. Similarly, no associations were observed between bladder cancer and total intake for any of the minerals reported in Table 3, including sodium, potassium, magnesium, calcium, phosphorus, and iron. Nor were there any detectable differences in the effects of any of the minerals and vitamins between invasive and non-invasive bladder cancer.

Analyses were repeated for all minerals and vitamins using measures taken from both dietary sources (excluding supplements) and supplements alone (data not shown). The only nutrient of interest to emerge from dietary sources alone when comparing highest quartiles of intake with lowest quartiles of intake, although not statistically significant was phosphorus (OR: 0.49 ; 95\% CI: $0.21-1.17$; $p$ trend $=0.13$ ). No other associations or trends could be observed for any of the other dietary or supplemental sources of minerals and vitamins.

We continued analyses for minerals and vitamins where an association had been indicated either from borderline 
Table 2 Calculated odds ratios (95\%) for total intake of vitamins and bladder cancer

\begin{tabular}{|c|c|c|c|c|c|}
\hline Daily intake & Q1 & Q2 & Q3 & Q4 & $p$ Trend \\
\hline Alpha-carotene $(\mu \mathrm{g})$ & $3.4-404$ & $404.1-647.13$ & $647.14-1104.70$ & $\geq 1104.71$ & 0.26 \\
\hline Cases/controls & $76 / 59$ & $89 / 60$ & $77 / 61$ & $77 / 59$ & \\
\hline ORs (95\% CI) & 1.00 & $1.33(0.77-2.30)$ & $1.19(0.68-2.11)$ & $1.48(0.83-2.64)$ & \\
\hline Beta-carotene $(\mu \mathrm{g})$ & 292.29-2294.21 & $2294.22-3773.80$ & $3773.81-5517.20$ & $\geq 5517.21$ & 0.90 \\
\hline Cases/controls & $94 / 59$ & $78 / 61$ & $65 / 60$ & $79 / 59$ & \\
\hline ORs $(95 \% \mathrm{CI})$ & 1.00 & $0.87(0.50-1.50)$ & $0.80(0.46-1.39)$ & $0.99(0.56-1.72)$ & \\
\hline Beta-cryptoxanthin $(\mu \mathrm{g})$ & $0-52.60$ & $52.61-125.77$ & $125.78-215.71$ & $\geq 215.72$ & 0.65 \\
\hline Cases/controls & $109 / 59$ & $76 / 61$ & $59 / 58$ & $78 / 61$ & \\
\hline ORs $(95 \% \mathrm{CI})$ & 1.00 & $0.69(0.40-1.20)$ & $0.66(0.37-1.16)$ & $0.87(0.50-1.53)$ & \\
\hline Lycopene $(\mu \mathrm{g})$ & $0-3092.68$ & $3092.69-4827$ & $4828-7746.43$ & $\geq 7746.44$ & 0.74 \\
\hline Cases/controls & $89 / 59$ & $73 / 60$ & $72 / 60$ & $88 / 60$ & \\
\hline ORs $(95 \% \mathrm{CI})$ & 1.00 & $0.96(0.55-1.66)$ & $0.70(0.39-1.24)$ & $0.98(0.55-1.73)$ & \\
\hline Lutein $(\mu \mathrm{g})$ & $0.93-1261.48$ & 1261.49-1942.44 & $1942.45-3134.85$ & $\geq 3134.86$ & 0.66 \\
\hline Cases/controls & $116 / 58$ & $61 / 61$ & $74 / 60$ & $70 / 59$ & \\
\hline ORs $(95 \% \mathrm{CI})$ & 1.00 & $0.52(0.30-0.90)$ & $0.76(0.45-1.31)$ & $0.80(0.46-1.40)$ & \\
\hline Total carotenoids $(\mu \mathrm{g})$ & $398.26-8879.22$ & $8879.23-12900.60$ & $12900.61-17932.72$ & $\geq 17932.73$ & 0.47 \\
\hline Cases/controls & $107 / 59$ & $73 / 60$ & $52 / 60$ & $87 / 60$ & \\
\hline ORs (95\% CI) & 1.00 & $0.70(0.41-1.21)$ & $0.49(0.27-0.86)$ & $0.90(0.51-1.59)$ & \\
\hline Vitamin D (IU) & $15.53-171.74$ & $171.75-388.90$ & $388.91-641.12$ & $\geq 641.13$ & 0.22 \\
\hline Cases/controls & $89 / 59$ & $72 / 60$ & $100 / 60$ & $61 / 60$ & \\
\hline ORs (95\% CI) & 1.00 & $0.78(0.44-1.38)$ & $1.03(0.60-1.76)$ & $0.58(0.31-1.06)$ & \\
\hline Vitamin E (mg) & $1.13-7.26$ & $7.27-20.94$ & $20.95-193.35$ & $\geq 193.36$ & 0.09 \\
\hline Cases/controls & $77 / 57$ & $95 / 58$ & $81 / 57$ & $54 / 57$ & \\
\hline ORs $(95 \% \mathrm{CI})$ & 1.00 & $1.19(0.68-2.08)$ & $0.88(0.49-1.56)$ & $0.66(0.36-1.20)$ & \\
\hline Thiamin (mg) & $0.21-1.32$ & $1.33-2.11$ & $2.12-3.34$ & $\geq 3.35$ & 0.50 \\
\hline Cases/controls & $91 / 58$ & $63 / 59$ & $99 / 63$ & $67 / 58$ & \\
\hline ORs $(95 \% \mathrm{CI})$ & 1.00 & $0.53(0.29-0.96)$ & $0.97(0.56-1.68)$ & $0.63(0.35-1.14)$ & \\
\hline Riboflavin (mg) & $0.25-1.63$ & $1.64-2.75$ & $2.76-4.04$ & $\geq 4.05$ & 0.61 \\
\hline Cases/controls & $85 / 60$ & $74 / 59$ & $91 / 61$ & $71 / 59$ & \\
\hline ORs $(95 \% \mathrm{CI})$ & 1.00 & $0.73(0.41-1.29)$ & $1.02(0.58-1.77)$ & $0.75(0.42-1.34)$ & \\
\hline Niacin (B3) (mg) & $5.77-21.91$ & 21.92-33.07 & $33.08-46.50$ & $\geq 46.51$ & 0.23 \\
\hline Cases/controls & $90 / 58$ & $68 / 60$ & $93 / 60$ & $67 / 60$ & \\
\hline ORs $(95 \%$ CI $)$ & 1.00 & $0.59(0.33-1.06)$ & $0.94(0.54-1.64)$ & $0.56(0.31-1.02)$ & \\
\hline Vitamin B6 (mg) & $0.32-1.94$ & $1.95-3.28$ & $3.29-4.88$ & $\geq 4.89$ & 0.41 \\
\hline Cases/controls & $93 / 59$ & $75 / 59$ & $77 / 61$ & $75 / 59$ & \\
\hline ORs $(95 \% \mathrm{CI})$ & 1.00 & $0.67(0.38-1.18)$ & $0.82(0.47-1.44)$ & $0.72(0.41-1.27)$ & \\
\hline Vitamin B12 $(\mu \mathrm{g})$ & $0.75-5.51$ & $5.52-10.82$ & $10.83-18.0$ & $\geq 18.1$ & 0.75 \\
\hline Cases/controls & $79 / 60$ & $89 / 60$ & $65 / 60$ & $87 / 59$ & \\
\hline ORs (95\% CI) & 1.00 & $1.30(0.75-2.26)$ & $0.84(0.47-1.51)$ & $1.05(0.60-1.84)$ & \\
\hline Folate $(\mu \mathrm{g})$ & $48.41-339.03$ & $339.04-579.10$ & $579.11-819.50$ & $\geq 819.51$ & 0.43 \\
\hline Cases/controls & $82 / 59$ & $82 / 61$ & $85 / 59$ & $71 / 60$ & \\
\hline ORs (95\% CI) & 1.00 & $0.83(0.47-1.46)$ & $0.91(0.53-1.56)$ & $0.74(0.40-1.35)$ & \\
\hline Vitamin C (mg) & $14.61-113.03$ & $113.04-190.25$ & $190.26-366.10$ & $\geq 366.11$ & 0.42 \\
\hline Cases/controls & $98 / 58$ & $78 / 60$ & $80 / 61$ & $62 / 59$ & \\
\hline ORs (95\% CI) & 1.00 & $0.83(0.48-1.43)$ & $0.84(0.48-1.45)$ & $0.78(0.45-1.38)$ & \\
\hline
\end{tabular}

$O R$ odds ratios, $C I$ confidence intervals, adjusted for age, sex, smoking status: current versus non-current smoker, pack years smoked (categories: $0-10,10-20,20-30,30-40,40-50,50+$ ), and total energy intake (quartiles kcal/day) 
Table 3 Calculated odds ratios (95\%) for total intake of minerals and bladder cancer

\begin{tabular}{cllll}
\hline Daily intake & Q1 & Q2 & Q3 & Q4 \\
\hline Sodium (mg) & $344.61-1484.83$ & $1484.84-1898.64$ & $1898.65-2372.65$ & $\geq 2372.66$ \\
Cases/controls & $78 / 58$ & $64 / 60$ & $59 / 60$ & $119 / 60$ \\
ORs (95\% CI) & 1.00 & $1.17(0.61-2.23)$ & $1.00(0.48-2.12)$ & $1.66(0.70-3.92)$ \\
Potassium (mg) & $535.63-2382.5$ & $2382.6-2874.24$ & $2874.25-3781.33$ & $\geq 3781.34$ \\
Cases/controls & $101 / 59$ & $45 / 60$ & $95 / 61$ & $80 / 59$ \\
ORs (95\% CI) & 1.00 & $0.50(0.27-0.91)$ & $1.03(0.53-2.0)$ & $0.65(0.29-1.45)$ \\
Calcium (mg) & $86.63-600.36$ & $600.37-918.23$ & $918.24-1346.4$ & $\geq 1346.5$ \\
Cases/controls & $99 / 59$ & $73 / 60$ & $90 / 59$ & $60 / 60$ \\
ORs (95\% CI) & 1.00 & $0.60(0.35-1.05)$ & $0.88(0.50-1.53)$ & $0.60(0.32-1.13)$ \\
Magnesium (mg) & $58.76-259.03$ & $259.04-328.08$ & $328.09-418.58$ & $\geq 418.59$ \\
Cases/controls & $95 / 59$ & $62 / 61$ & $83 / 60$ & $80 / 59$ \\
ORs (95\% CI) & 1.00 & $0.65(0.36-1.15)$ & $0.79(0.43-1.44)$ & $0.56(0.27-1.16)$ \\
Phosphorus (mg) & $177.85-965.2$ & $965.3-1195.67$ & $1195.68-1556.5$ & $\geq 1556.6$ \\
Cases/controls & $93 / 60$ & $65 / 59$ & $81 / 61$ & $83 / 59$ \\
ORs (95\% CI) & 1.00 & $1.02(0.55-1.92)$ & $0.93(0.44-1.98)$ & $0.70(0.28-1.75)$ \\
Iron (mg) & $2.12-11.25$ & $11.26-15.56$ & $15.57-23.20$ & 0.27 \\
Cases/controls & $82 / 59$ & $75 / 60$ & $77 / 60$ & 0.20 \\
ORs (95\% CI) & 1.00 & $1.04(0.57-1.90)$ & $0.92(0.49-1.73)$ & $1.06(0.57-1.96)$ \\
\hline OR & & 23.21 & 0.93
\end{tabular}

$O R$ odds ratios, $C I$ confidence intervals, adjusted for age, sex, smoking status: current versus non-current smoker, pack years smoked (categories: $0-10,10-20,20-30,30-40,40-50,50+$ ), and total energy intake (quartiles kcal/day)

associations and biological plausibility or from previous studies. Minerals and vitamins that met the criteria were investigated for interactions with smoking characteristics and age, which were both adjusted for each other. The joint effects of nutrient intake and established risk factors e.g., smoking status (ever/never), cigarettes per day $(<20 / \geq 20 /$ day), duration of smoking ( $<27$ years $/ \geq 27$ years), and age $(<63$ years $/ \geq 63$ years) are presented in Table 4 . The OR for heavy cigarette smokers ( $\geq 20$ cigarettes per day) in the highest group for total intake of vitamin E, was 0.58 (95\%: $0.34-0.99 ; p$ interaction 0.03 ). Inverse associations of borderline statistical significance were also observed among heavy smokers for the highest intake of total carotenoids (OR: $0.62 ; 95 \%$ CI: $0.36-1.09 ; p$ interaction 0.08 ) and niacin (OR: 0.66 ; $95 \%$ CI: $0.39-1.14$; $p$ interaction 0.08). Interaction between thiamin intake and the number of cigarettes smoked per day was also of borderline statistical significance. Possible reductions in risk of bladder cancer for older participants were also associated with higher intakes of total carotenoids (OR: $0.59 ; 95 \% \mathrm{CI}$ : $0.35-0.99$ ), vitamin $\mathrm{D}$, thiamin, and niacin ( $p$ interaction: $0.04,0.02$, and 0.03 , respectively). No other statistically significant associations were observed, although there were reduced odds of bladder cancer among the older age group for the highest intake of vitamin E (OR: 0.61; 95\% CI: 0.37-1.02) and interactions between vitamin $\mathrm{C}$ and ever-smoking $(p=0.08)$ and vitamin $\mathrm{C}$ and age $(p=0.08)$ were borderline (data not shown).

The statistically significant inverse associations observed between total intake of carotenoids, vitamin D, thiamin, and niacin and the risk of bladder cancer for older individuals remained robust following the FPRP test. Each inverse association had less than a 50\% likelihood of being false positive for an odds ratio of 1.5 and based on a prior probability of $25 \%$,

\section{Discussion}

Main findings

We investigated an extensive range of micronutrients in relation to the risk of bladder cancer. Possible inverse associations of borderline statistical significance were observed between bladder cancer and total intake of vitamin $\mathrm{E}$ and dietary phosphorus. We found some evidence that total intake of vitamin $\mathrm{E}$, total carotenoids, niacin and possibly thiamin might be modified by cigarette smoking in that inverse associations were observed largely among heaviest smokers. Higher intakes of carotenoids, vitamin $\mathrm{D}$, thiamin, niacin, and vitamin $\mathrm{E}$ were also associated with reduced odds of bladder cancer in the older age group. No 


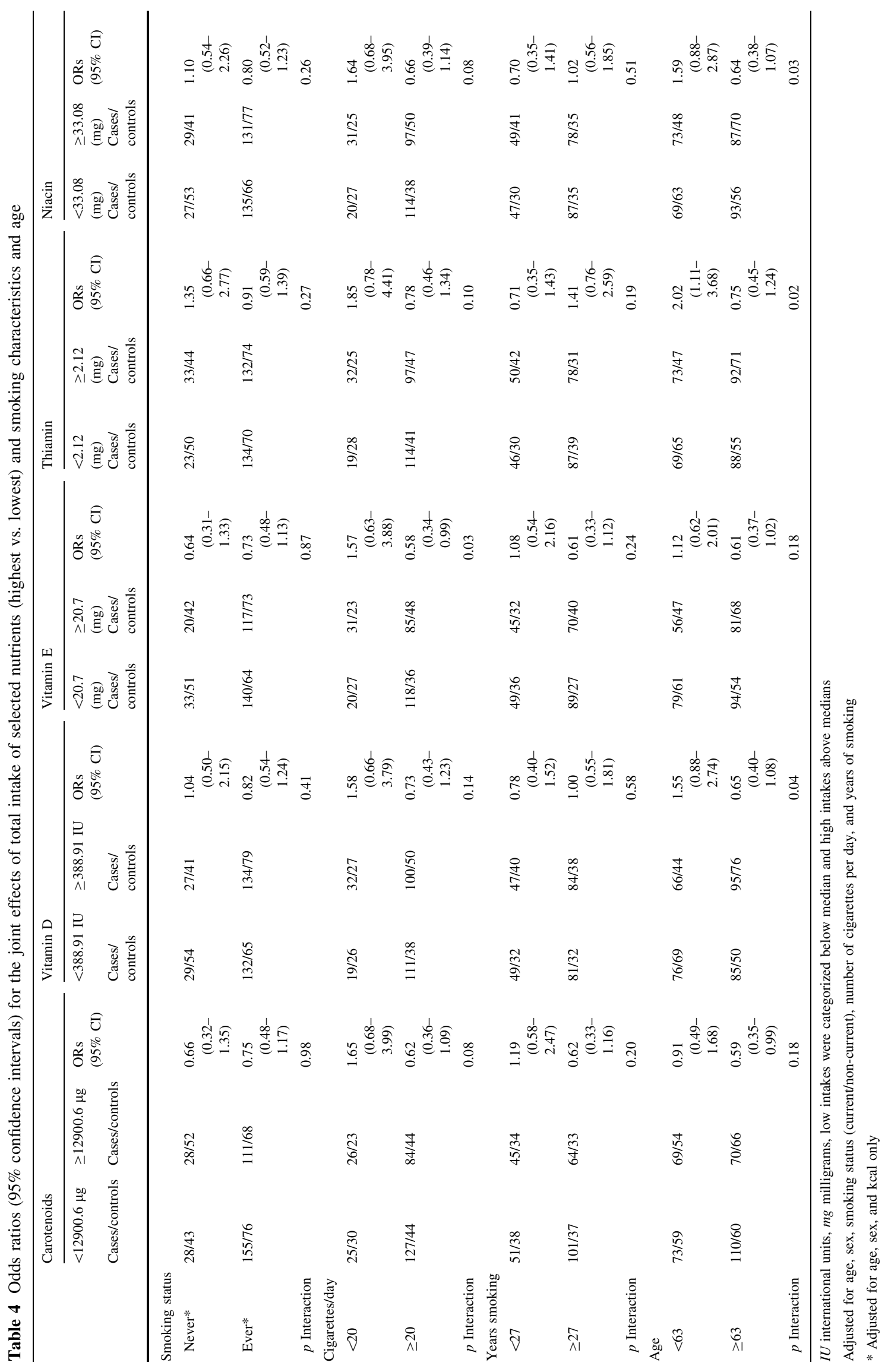


other associations were apparent between bladder cancer and any other mineral or vitamin.

Previous findings

The potentially protective effect of vitamin $\mathrm{E}$ that we observed against developing bladder cancer was consistent with findings from two other US studies [20, 27]. However, we detected no association between risk of bladder cancer overall and the intake of carotenoids either as individual carotenoids $(\alpha$-carotene, $\beta$-carotene, $\beta$-cryptoxanthin, lycopene, and lutein/zeaxanthin) or collectively as total carotenoid intake. Our findings were in agreement with an intervention study [31], a meta-analysis [10], two prospective studies [3, 20], and one case-control study [30]. Conversely, four case-control studies [8, 22, 23, 48] observed inverse associations with carotenoid intake and two other prospective studies [21, 25] found specific carotenoids, dietary beta-carotene [25] and beta-cryptoxanthin [21] to be possibly protective.

Like previous studies, we investigated the most common carotenoids from an estimated 40 carotenoids present in the human diet [22]. Each carotenoid is considered to have a specific biological function [22]. While some carotenoids have potential to form vitamin A (provitamin A carotenoids include, $\alpha$-carotene, $\beta$-carotene, and $\beta$-cryptoxanthin) others do not have this capability (non-provitamin A carotenoids are lycopene, lutein, and zeaxanthin) [15]. Contrary to an earlier study [22], we did not find either of these two categories of carotenoids to be associated with the risk of bladder cancer (data not shown). Any chemopreventive effect may be difficult to detect for individual carotenoids either due to the relatively small sample size, small size of the effect or because carotenoids possibly only work in synergy with each other or other dietary factors [49].

Where a relatively large prospective study of US men [20] and a case-control study [23] both reported no association between vitamin $\mathrm{D}$ and bladder cancer, we observed reduced odds of bladder cancer with higher intake of vitamin D; although this was not statistically significant. The anti-proliferative effect of vitamin $\mathrm{D}$ has been shown in various in vitro and in vivo investigations [50]. However, as vitamin $\mathrm{D}$ is available from both dietary sources and UV-B radiation [50], it is difficult to estimate the full effect of vitamin D without taking into account sunlight exposure.

Although B-group vitamins are thought to possibly offer protection via their role in genomic stability, DNA repair, and regulation of cell division [15], we did not detect any associations between any B-group vitamin and bladder cancer overall. This was consistent with three previous prospective studies $[20,21,25]$ and one retrospective study
[23] but disagreed with two other recent case-control studies [28, 35]. We also failed to detect any association between bladder cancer and another water-soluble vitamin with antioxidant potential, vitamin $\mathrm{C}$. Once again, there were conflicting reports relating to the effect of vitamin $\mathrm{C}$ on bladder cancer risk among the various studies [3, 8, 19$21,23,29,32,33]$. When reviewing the existing literature on vitamin $\mathrm{C}$ and many of the other vitamins, any evidence for an association generally appeared to be weaker in prospective studies compared with case-control studies [7]. Lack of association between some micronutrients and bladder cancer might also be due to collinearity among nutrients as a result of shared food sources [51]. For instance, many fruits and vegetables rich in carotenoids are also good sources of vitamin $\mathrm{C}$, potassium, and folate.

To our knowledge, phosphorus has been investigated in relation to bladder cancer in only one other epidemiological study [20] that reported no association following multivariate analyses. Although we observed an approximate $50 \%$ reduction in the odds of bladder cancer associated with higher dietary intake of phosphorus, it was not statistically significant. Given this ubiquitous micronutrient is an important physiological component of DNA, RNA, ATP, and cell membranes, it may be worthy of further consideration [52].

In our study, a higher intake of vitamin E related to a reduced risk of bladder cancer among heaviest smokers, a finding consistent with those reported in another American case-control study [27]. The reduced odds of bladder cancer we observed for the highest quartile of total carotenoids among the heaviest smokers also agrees with results presented in another case-control study conducted in the USA [8]. Two additional American case-control studies [22, 48] also reported increased risk of bladder cancer among smokers with the lower intakes of total [22] and specific carotenoids, lutein, and zeaxanthin [48]. Castelao et al. [8] suggested that carotenoids provide protection against bladder cancer for smokers by detoxifying arylamines. Borderline statistically significant interactions between the number of cigarettes smoked per day and intakes of thiamin and niacin may warrant further investigation.

Our findings indicate that higher intakes of vitamin D, thiamin, niacin, carotenoids, and possibly vitamin E may be beneficial to participants in the older age group. Older individuals may have limited access to regular sunshine (e.g., living in institutions) and therefore have to rely strongly on dietary sources of vitamin D and supplementation. Bladder cancer is a disease that typically affects older people [53], and bioavailability of B-group vitamins may be compromised in this demographic by certain drugs (e.g., acid lowering agents) [54]. Additionally, vitamin E, like carotenoids acts as an antioxidant and, as suggested by 
our results, could be more beneficial under conditions of the greatest oxidative stress such as smoking and aging [27].

\section{Strengths and limitations}

There were limitations associated with our study. Like most case-control studies, potential for recall bias is a consideration in dietary estimation. However, as dietary factors are not commonly associated with bladder cancer etiology recall of dietary intake is likely to be non-differential between cases and controls. Other potential limitations relating to measurement of dietary exposures include only one dietary collection period and the possibility of preclinical disease altering dietary intake. Although there was only one collection period, dietary data were collected using a detailed and validated FFQ [43]. As for dietary change, a majority of the cases in our study were diagnosed with superficial bladder cancer, and it is considered unlikely that preclinical disease would alter dietary behavior [28]. Although we cannot totally exclude the possibility of recall bias, dietary intake for major dietary components; calories, total fat, alcohol, and coffee were comparable between cases and controls suggesting that it should be minimal.

Finally, controls were drawn from two sourcesDepartment of Transportation (for those under 65 years) and Medicare (for those 65 years and older). These are considered nearly complete sources of records in our population. Among cases, over $95 \%$ report having a driver's license (for those under 65 years) as do over $95 \%$ (of those 65 years and older) report being enrolled in Medicare (data not shown). We examined the characteristics of controls younger than 65 years and over 65 years and found them to be comparable with respect to sex, smoking, and medical access variables (i.e., visit to a doctor in the past 2 years); however, older subjects had less than a college education (40\% of those under 65 years and $50 \%$ of those 65 years and older). However, level of education is not a strong risk factor for bladder cancer (including in our own data) and thus was not considered a potential confounder in our analysis.

While multiple comparisons were made in this study, we attempted to address this issue by utilizing the FPRP [46]. Statistically significant associations between higher intakes of carotenoids, vitamin D, thiamin, and niacin and risk of bladder cancer among the older individuals remained robust following this test. Although it is worth noting that statistical power was low and determining appropriate prior probabilities is difficult [55]. Biologically plausible mechanisms of action and similar results reported from other studies provide additional support for some of our findings $[8,20,27]$.

\section{Conclusion}

In conclusion, the effects of vitamin E, carotenoids, vitamin $\mathrm{D}$, thiamin, and niacin in relation to the risk of developing bladder cancer may warrant further investigation. Future studies should focus on optimal doses and combinations of these micronutrients particularly for high risk groups such as heavy smokers and older individuals.

Acknowledgments We would like to thank the physicians, pathology laboratories, staff members, and many participants of the New Hampshire Health Study for making this study possible.

Financial Support This publication was funded in part by grant numbers 5 P42 ES007373 from the National Institute of Environmental Health Sciences, NIH and CA57494 from the National Cancer Institute, NIH. Its contents are solely the responsibility of the authors and do not necessarily represent the official views of the NIEHS, NIH. Professor Zeegers was partly funded by Cancer Research UK.

Conflict of Interest The authors declare no conflict of interest.

Open Access This article is distributed under the terms of the Creative Commons Attribution Noncommercial License which permits any noncommercial use, distribution, and reproduction in any medium, provided the original author(s) and source are credited.

\section{References}

1. Parkin DM, Bray F, Ferlay J, Pisani P (2005) Global cancer statistics, 2002. CA Cancer J Clin 55:74-108

2. National Cancer Institute (NCI) (2009) US National Institutes of Health. [cited 2009 October 20]; Available from: www.cancer. gov

3. Holick CN, De Vivo I, Feskanich D, Giovannucci E, Stampfer M, Michaud DS (2005) Intake of fruits and vegetables, carotenoids, folate, and vitamins A, C, E and risk of bladder cancer among women (United States). Cancer Causes Control 16:1135-1145

4. Grossman HB, Stenzl A, Moyad MA, Droller MJ (2008) Bladder cancer: chemoprevention, complementary approaches and budgetary considerations. Scand J Urol Nephrol Suppl 42: 213-233

5. Pelucchi C, Bosetti C, Negri E, Malvezzi M, La Vecchia C (2006) Mechanisms of disease: the epidemiology of bladder cancer. Nat Clin Pract Urol 3:327-340

6. Brown LM, Zahm SH, Hoover RN, Fraumeni JF Jr (1995) High bladder cancer mortality in rural New England (United States): an etiologic study. Cancer Causes Control 6:361-368

7. Riboli E, Norat T (2003) Epidemiologic evidence of the protective effect of fruit and vegetables on cancer risk. Am J Clin Nutr 78:559S-569S

8. Castelao JE, Yuan JM, Gago-Dominguez M et al (2004) Carotenoids/vitamin $\mathrm{C}$ and smoking-related bladder cancer. Int $\mathrm{J}$ Cancer 110:417-423

9. Zeegers MP, Goldbohm RA, van den Brandt PA (2001) Consumption of vegetables and fruits and urothelial cancer incidence: a prospective study. Cancer Epidemiol Biomarkers Prev 10:1121-1128

10. Steinmaus CM, Nunez S, Smith AH (2000) Diet and bladder cancer: a meta-analysis of six dietary variables. Am J Epidemiol 151:693-702 
11. Sacerdote C, Matullo G, Polidoro S et al (2007) Intake of fruits and vegetables and polymorphisms in DNA repair genes in bladder cancer. Mutagenesis 22:281-285

12. Lin J, Kamat A, Gu J et al (2009) Dietary intake of vegetables and fruits and the modification effects of GSTM1 and NAT2 genotypes on bladder cancer risk. Cancer Epidemiol Biomarkers Prev 18:2090-2097

13. Tang L, Zirpoli GR, Guru K et al (2008) Consumption of raw cruciferous vegetables is inversely associated with bladder cancer risk. Cancer Epidemiol Biomarkers Prev 17:938-944

14. Kellen E, Zeegers M, Paulussen A, Van Dongen M, Buntinx F (2006) Fruit consumption reduces the effect of smoking on bladder cancer risk. The Belgian case control study on bladder cancer. Int J Cancer 118:2572-2578

15. World Cancer Research Fund/American Institute for Cancer (2007) Food, nutrition, physical activity, and the prevention of cancer: a global perspective. AICR, Washington DC

16. Brinkman M, Zeegers MP (2008) Nutrition, total fluid and bladder cancer. Scand J Urol Nephrol Suppl 42:25-36

17. Steineck G, Hagman U, Gerhardsson M, Norell SE (1990) Vitamin A supplements, fried foods, fat and urothelial cancer. A case-referent study in Stockholm in 1985-1987. Int J Cancer 45:1006-1011

18. La Vecchia C, Negri E, Decarli A, D’Avanzo B, Liberati C, Franceschi S (1989) Dietary factors in the risk of bladder cancer. Nutr Cancer 12:93-101

19. Michaud DS, Pietinen P, Taylor PR, Virtanen M, Virtamo J, Albanes D (2002) Intakes of fruits and vegetables, carotenoids and vitamins $\mathrm{A}, \mathrm{E}, \mathrm{C}$ in relation to the risk of bladder cancer in the ATBC cohort study. Br J Cancer 87:960-965

20. Michaud DS, Spiegelman D, Clinton SK, Rimm EB, Willett WC, Giovannucci EL (2000) Prospective study of dietary supplements, macronutrients, micronutrients, and risk of bladder cancer in US men. Am J Epidemiol 152:1145-1153

21. Zeegers MP, Goldbohm RA, van den Brandt PA (2001) Are retinol, vitamin $\mathrm{C}$, vitamin $\mathrm{E}$, folate and carotenoids intake associated with bladder cancer risk? Results from the Netherlands Cohort Study. Br J Cancer 85:977-983

22. Schabath MB, Grossman HB, Delclos GL et al (2004) Dietary carotenoids and genetic instability modify bladder cancer risk. J Nutr 134:3362-3369

23. Vena JE, Graham S, Freudenheim J et al (1992) Diet in the epidemiology of bladder cancer in western New York. Nutr Cancer 18:255-264

24. La Vecchia C, Negri E (1996) Nutrition and bladder cancer. Cancer Causes Control 7:95-100

25. Roswall N, Olsen A, Christensen J, Dragsted LO, Overvad K, Tjonneland A (2009) Micronutrient intake and risk of urothelial carcinoma in a prospective Danish cohort. Eur Urol 56:764-770

26. Riboli E, Gonzalez CA, Lopez-Abente G et al (1991) Diet and bladder cancer in Spain: a multi-centre case-control study. Int $\mathrm{J}$ Cancer 49:214-219

27. Liang D, Lin J, Grossman HB et al (2008) Plasma vitamins E and $\mathrm{A}$ and risk of bladder cancer: a case-control analysis. Cancer Causes Control 19:981-992

28. Garcia-Closas R, Garcia-Closas M, Kogevinas M et al (2007) Food, nutrient and heterocyclic amine intake and the risk of bladder cancer. Eur J Cancer 43:1731-1740

29. Bruemmer B, White E, Vaughan TL, Cheney CL (1996) Nutrient intake in relation to bladder cancer among middle-aged men and women. Am J Epidemiol 144:485-495

30. Garcia R, Gonzalez CA, Agudo A, Riboli E (1999) High intake of specific carotenoids and flavonoids does not reduce the risk of bladder cancer. Nutr Cancer 35:212-214

31. Virtamo J, Edwards BK, Virtanen M et al (2000) Effects of supplemental alpha-tocopherol and beta-carotene on urinary tract cancer: incidence and mortality in a controlled trial (Finland). Cancer Causes Control 11:933-939

32. Nomura AM, Kolonel LN, Hankin JH, Yoshizawa CN (1991) Dietary factors in cancer of the lower urinary tract. Int J Cancer 48:199-205

33. Shibata A, Paganini-Hill A, Ross RK, Henderson BE (1992) Intake of vegetables, fruits, beta-carotene, vitamin $\mathrm{C}$ and vitamin supplements and cancer incidence among the elderly: a prospective study. Br J Cancer 66:673-679

34. Ames BN (2001) DNA damage from micronutrient deficiencies is likely to be a major cause of cancer. Mutat Res 475:7-20

35. Schabath MB, Spitz MR, Lerner SP et al (2005) Case-control analysis of dietary folate and risk of bladder cancer. Nutr Cancer 53:144-151

36. Cohen SM (1995) Role of urinary physiology and chemistry in bladder carcinogenesis. Food Chem Toxicol 33:715-730

37. Michaud DS, Clinton SK, Rimm EB, Willett WC, Giovannucci E (2001) Risk of bladder cancer by geographic region in a U.S. cohort of male health professionals. Epidemiology 12: 719-726

38. Karagas MR, Tosteson TD, Blum J, Morris JS, Baron JA, Klaue B (1998) Design of an epidemiologic study of drinking water arsenic exposure and skin and bladder cancer risk in a U.S. population. Environ Health Perspect 106:1047-1050

39. Fortuny J, Kogevinas M, Zens MS et al (2007) Analgesic and anti-inflammatory drug use and risk of bladder cancer: a population based case control study. BMC Urol 7:13

40. Applebaum KM, Karagas MR, Hunter DJ et al (2007) Polymorphisms in nucleotide excision repair genes, arsenic exposure, and non-melanoma skin cancer in New Hampshire. Environ Health Perspect 115:1231-1236

41. Karagas MR, Park S, Warren A et al (2005) Gender, smoking, glutathione-S-transferase variants and bladder cancer incidence: a population-based study. Cancer Lett 219:63-69

42. Karagas MR, Stukel TA, Morris JS et al (2001) Skin cancer risk in relation to toenail arsenic concentrations in a US populationbased case-control study. Am J Epidemiol 153:559-565

43. Salvini S, Hunter DJ, Sampson L et al (1989) Food-based validation of a dietary questionnaire: the effects of week-to-week variation in food consumption. Int J Epidemiol 18:858-867

44. Michaud DS, Spiegelman D, Clinton SK, Rimm EB, Willett WC, Giovannucci EL (1999) Fruit and vegetable intake and incidence of bladder cancer in a male prospective cohort. J Natl Cancer Inst 91:605-613

45. United States Department of Agriculture (USDA) (1993) Composition of foods-raw, processed and prepared, 1963-1992: agricultural handbook no. 8 series. Department of Agriculture, Washington, DC

46. Wacholder S, Chanock S, Garcia-Closas M, El Ghormli L, Rothman N (2004) Assessing the probability that a positive report is false: an approach for molecular epidemiology studies. J Natl Cancer Inst 96:434-442

47. Kellen E, Zeegers M, Paulussen A et al (2007) Does occupational exposure to PAHs, diesel and aromatic amines interact with smoking and metabolic genetic polymorphisms to increase the risk on bladder cancer?; The Belgian case control study on bladder cancer risk. Cancer Lett 245:51-60

48. Hung RJ, Zhang ZF, Rao JY et al (2006) Protective effects of plasma carotenoids on the risk of bladder cancer. J Urol 176: 1192-1197

49. Messina M, Lampe JW, Birt DF et al (2001) Reductionism and the narrowing nutrition perspective: time for reevaluation and emphasis on food synergy. J Am Diet Assoc 101:1416-1419

50. Konety BR, Lavelle JP, Pirtskalaishvili G et al (2001) Effects of vitamin $\mathrm{D}$ (calcitriol) on transitional cell carcinoma of the bladder in vitro and in vivo. J Urol 165:253-258 
51. Willett W (2003) Invited commentary: OPEN question. Am J Epidemiol 158:22-24

52. Berndt TJ, Schiavi S, Kumar R (2005) "Phosphatonins" and the regulation of phosphorus homeostasis. Am J Physiol Renal Physiol 289:F1170-F1182

53. Kirkali Z, Chan T, Manoharan M et al (2005) Bladder cancer: epidemiology, staging and grading, and diagnosis. Urology 66: 4-34
54. Dharmarajan TS, Kanagala MR, Murakonda P, Lebelt AS, Norkus EP (2008) Do acid-lowering agents affect vitamin B12 status in older adults? J Am Med Dir Assoc 9:162-167

55. Matullo G, Berwick M, Vineis P (2005) Gene-environment interactions: how many false positives? J Natl Cancer Inst 97:550-551 